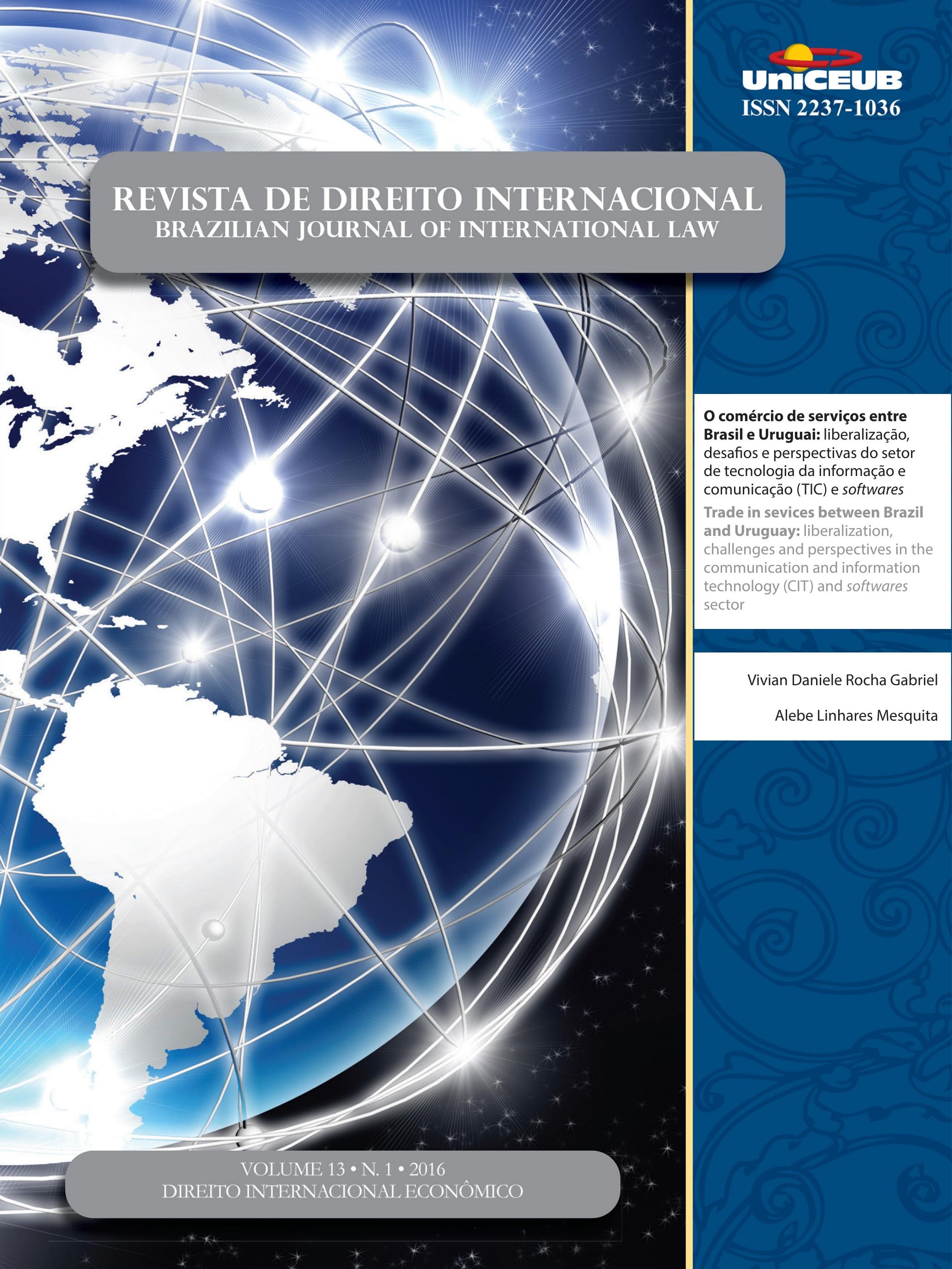




\section{Sumário}

Dossiê Temático: Direito Internacional Econômico.........................................................1

EDITORIAL:

Resultados da III Conferência Bienal da Red DEI ................................................. 3

Michelle Ratton Sanchez-Badin (em nome da Diretoria da Red DEI), Fabio Costa Morosini e Lucas da Silva Tasquetto (em nome dos organizadores da III Conferência da Red DEI)

Direito Internacional Econômico no Brasil: QUem Somos E o QUE faZemos? EvidênCIas EMPÍRICAS DE 1994 A 2014

Michelle Ratton Sanchez Badin, Fabio Costa Morosini e Inaê Siqueira de Oliveira

UM ESPAÇO PARA PENSAR EM ALTERNATIVAS? A ACADEMIA LATINO-AMERICANA DE DIREITO INTERNACIONAL ECONÔMICO FRENTE À ORDEM ECONÔMICA GLOBAL

Nicolás Marcelo Perrone

Grupo de alto Nível Brasil - Urugua (GAN): um Novo paradigma para a INTEgraÇão PRODUTIVA NO MERCOSUL

Alebe Linhares Mesquita e Vivian Daniele Rocha Gabriel

O COMÉRCIO de SERVIÇOS ENTRE Brasil E URUGUAI: LiberalizaÇÃo, DESAFIOS E PERSPECTIVAS DO SETOR DE TECNOLOGIA DA INFORMAÇÃO E COMUNICAÇÃO (TIC) E SOFTWARES

Vivian Daniele Rocha Gabriel e Alebe Linhares Mesquita

Core Labor Standards No Regime de PREFERÊNCIAS TARIFÁrias No MERCOSUL: A NeCESSIDADE DE HUMANIZAÇÃO DO COMÉRCIO INTERNACIONAL

Martinho Martins Botelho e Marco Antônio César Villatore

ACordo TRIMS: FleXibilizaÇão ou Não? Política de CONTEÚdo loCal, PROCESSO PROdUTIVO BÁSICO (PPB) E OS DESAFIOS PARA A INDÚSTRIA BRASILEIRA E A INTEGRAÇÃo LATINO-AMERICANA 100

Natália Figueiredo 
ESTUDIOS DE CASO DE RECHAZOS EN FRONTERA DE EXPORTACIONES ALIMENTARIAS LATINOAMERICANAS POR MOTIVOS RELACIONADOS CON MEDIDAS TÉCNICAS NO ARANCELARIAS.

Sofía Boza, Juan Rozas e Rodolfo Rivers

América do Sul em face dos tratados bilaterais de inVESTimento: RUMO aO RETORNo do EsTADO NA SOLUÇão DE CONTROvÉRSIAS? 133 Magdalena Bas

FutURo DE LOS SISTEMAS NACIONALES DE CIENCIA TECNOLOGÍA E INNOVACIÓN EN LA AGENDA ECONÓMICA DE AMÉRICA LATINA: DEFINIENDO CAMBIOS REGULATORIOS O PROTEGIENDO INVERSIONES 146

Rodrigo Corredor

EL PAPEL DE LAS INSTITUCIONES DE CONTROL FINANCIERO SOBRE LOS DERECHOS HUMANOS EN EL CONTEXTO LATINOAMERICANO 157 Jose Miguel Camacho Castro

CONVERGENCIA REgUlATORIA EN LA ALIANZA DEL PACÍFICO: UN CAPÍTULO INCONCLUSO 170 Rodrigo Polanco Lazo

O CONSTITUCIONALISMO E A COMUNITARIZAÇÃO NO DIREITO INTERNACIONAL: POSSIBILIDADES PARA O COMÉRCIO INTERNACIONAL?

Camilla Capucio

ESCASSEZ HÍDRICA E DIREITO INTERNACIONAL ECONÔMICO: O BRASIL COMO PROTAGONISTA NA TRANSFERÊNCIA DE ÁGUA PARA REGIÕES ÁRIDAS

Douglas de Castro

A Segurança energética como base para maior integração na América Do Sul: à espera DE UM TRATADO MULTILATERAL

Matheus Bassani

Outros Artigos. 246

As PRÁtICAS RESTRITIVAS DA CONCORRÊNCIA NO MERCADO DE CONTRATAÇÃo PÚBLICA EUROPEU .. 248 Alice Rocha da Silva e Ruth M. P. Santos 
Do TRANSNACIONAL PARA O NACIONAL: IOSCO, O MERCADO DE VALORES MOBILIÁRIOS BRASILEIRO E ACCOUNTABILITY

Salem Nasser, Nora Rachman e Viviane Muller Prado

MigRaÇÃo de TRABALHADORES INTELECTUAIS BRASILEIROS PARA O MERCADO INTERNACIONAL: IDENTIFICAÇÃO DE ATOS DE ALICIAMENTO DE EMPREGADOS E MECANISMOS LEGAIS PARA IMPEDIR A APROPRIAÇÃo TECNOLÓGICA E CONCORRÊNCIA DESLEAL ..........................................285 José Carlos Vaz e Dias e João Marcelo Sant'Anna da Costa

THE EASIER WAY TO HAVE "BETTER LAW"? THE MOST-SIGNIFICANT-RELATIONSHIP DOCTRINE AS THE FALLBACK CONFLICT-OF-LAW RULE IN THE PEOPLE'S REPUBLIC OF CHINA

Chi Chung

REFLEXOS JURÍDiCOS DA GOVERNANÇA GLOBAL SUBNACIONAL: A PARADIPLOMACIA E O DIREITO INTERNACIONAL: DESAFIO OU ACOMODAÇÃO 320

Valéria Cristina Farias e Fernando Rei

Matrizes Políticas da JUSTiÇA PENAL INTERNACIONAL. 341 Francisco Rezek

RESPONSABILIDAD INTERNACIONAL DEL ESTADO FRENTE A LUCHA CONTRA LA DISCRIMINACIÓN RACIAL Y ÉTNICA EN ESPAÑA. 348

Edilney Tomé da Mata e Eduardo Biacchi Gomes Correio

The Peace Process in Sierra Leone: an analysis on marriages between culture and CRIME

Gustavo Bussmann Ferreira

Funcionalização e expansão do Direito Penal: o Direito Penal negocial ...............376 Antonio Henrique Graciano Suxberger e Dermeval Farias Gomes Filho

Proteção Internacional do Consumidor e Cooperação Interjurisdicional .396 Héctor Valverde Santana e Sophia Martini Vial

The land rights of indigenous and traditional peoples in Brazil and Australia.... 418 Márcia Dieguez Leuzinger e Kylie Lyngard 
The reception of European ideas in Latin America: the issue of the German sources in Tobias Barreto, A Prominent nineteenth CENTURy BraZilian legal scholar........439 Arnaldo Sampaio de Moraes Godoy

Normas Editoriais ..................................................................................... 461 


\title{
O comércio de serviços entre Brasil e Uruguai: liberalização, desafios e perspectivas do setor de tecnologia da informação e comunicação (TIC) e softwares*
}

\author{
Trade in sevices between Brazil and Uruguay: \\ liberalization, challenges and perspectives \\ in the communication and information \\ technology (CIT) and softwares sector
}

Vivian Daniele Rocha Gabriel **

Alebe Linhares Mesquita***

\section{Resumo}

O presente artigo tem por objetivo analisar o comércio de serviços entre Brasil e Uruguai, mais especificamente, o setor de tecnologia da informação e comunicação (TIC) e softwares. Por conseguinte, este artigo encontra-se divido em 3 momentos distintos. Primeiramente, discorre-se sobre a regulação internacional do comércio de serviços, tanto no âmbito multilateral quanto no regional. Em seguida, promove-se um estudo sobre a realidade do comércio de serviços entre Brasil e Uruguai. Por fim, analisa-se o setor de tecnologia da informação e comunicação (TIC) e softwares e suas potenciais complementariedades que poderiam impulsionar o comércio entre os dois países. A metodologia adotada no desenvolvimento da pesquisa consistiu-se como teórica, bibliográfica, descritiva e exploratória. Em conclusão, pode-se afirmar que Brasil e Uruguai devem promover políticas de cooperação entre subsetores de serviços, particularmente o de TIC e softwares, fomentando a troca de tecnologia e a integração produtiva. O artigo se mostra original, visto que existem poucas análises jurídicas recentes sobre o comércio de serviços entre Brasil e Uruguai neste setor específico, podendo implicar futuras políticas públicas para a promoção do comércio entre os dois Estados.

Palavras-Chave: Serviços. Brasil. Uruguai. TIC. Softwares.

** Advogada. Doutoranda e Mestre em Direito Internacional pela Faculdade de Direito da Universidade de São Paulo (USP). Pesquisadora do Centro de Estudos de Estudos do Comércio Global e Investimentos (CCGI) da Escola de Economia de São Paulo da Fundação Getúlio Vargas (EESP/FGV). E-mail: vivian.d.rocha@ usp.br.

*** Advogado. Mestrando em Direito Internacional e Comparado pela Universidade de São Paulo (USP). Pesquisador do Centro de Estudos de Estudos do Comércio Global e Investimentos (CCGI) da Escola de Economia de São Paulo da Fundação Getúlio Vargas (EESP/ FGV). E-mail: alebe.mesquita@fgv.br.

\section{Abstract}

This paper aims to analyze the trade in services between Brazil and Uruguay, more specifically, the communication and information technology (CIT) and software sector. Therefore, this study is divided into three distinct moments. First, it addresses the international regulation on trade in services in the multilateral and in regional level. Subsequently, it promotes a study about the reality of trade in services between Brazil and Uruguay. At last, it analyses the communication and information technology (CIT) and software sector and its potential complementarities that could boost trade between 
the two countries. The methodology adopted in the development of this research is bibliography, descriptive and exploratory. In conclusion, it can be affirmed that Brazil and Uruguay should promote cooperation policies between services subsectors, particularly CIT and software, fostering the exchange of technology and production integration. The article is original, because there are few recent legal studies on trade in services between Brazil and Uruguay in the specific areas addressed, and may result in future public policies for promoting trade between the two countries.

Keywords: Services. Brazil. Uruguay. CIT. Softwares.

\section{INTRODUÇÃO}

O setor de serviços tem se tornado de fundamental importância no mundo globalizado, tendo se manifestado como elemento indispensável para o comércio internacional. Com o avanço de novas tecnologias de transmissão ao longo do século XX e início do século XXI, aliado às transformações econômicas liberalizantes efetuadas nos anos 1980 e 1990, algumas atividades, que antes se encontravam restritas apenas ao plano doméstico, passaram a se expandir e a ser comercializáveis, também, no plano internacional, como é o caso dos serviços bancários, de educação, de transporte, entre outros.

A internacionalização do setor de serviços, em geral, associa-se com a evolução da estrutura de produção global, com base na fragmentação das etapas da cadeia produtiva e da sua desconcentração. Cumpre observar que, atualmente, quanto maior a sofisticação e a complexidade do produto, mais elevada é a densidade tecnológica resultante no produto final e, consequentemente, o seu valor de mercado. Assim, quanto mais complexo o processo produtivo, mais elevada é a participação do setor de serviços informacionais na cadeia produtiva, de modo que a eficiência deste se torna essencial para a competitividade do país, alavancando a economia como um todo.

Atualmente, o setor de serviços representa a maior porcentagem do Produto Interno Bruto (PIB) das economias desenvolvidas e de boa parte das economias emergentes. No Mercosul, esse setor já ocupa a maior participação no PIB do bloco, se comparado aos setores primário e secundário. Embora a comercialização de serviços advindos dos Estados Partes do Mercosul não apresente a mesma intensidade verificada entre as nações desenvolvidas, observa-se um ritmo de crescimento anual significativo, tanto para o comércio intra quanto extra Mercosul.

Destarte, este artigo tem por objetivo analisar o comércio de serviços entre Brasil e Uruguai, mais especificamente, o setor de tecnologia da informação e comunicação (TIC) e softwares. Esse setor foi escolhido devido a sua importância para as economias dos dois países, bem como por serem essenciais à promoção de uma integração produtiva e à formação de cadeias globais de valor no mundo contemporâneo.

A opção por se estudar a realidade comercial desses dois países remete à criação, em junho de 2012, do Grupo de Alto Nível Brasil - Uruguai (GAN) voltado à consolidação de projetos em áreas prioritárias para $\mathrm{O}$ desenvolvimento da integração bilateral. Essas iniciativas se concentra, notadamente, nos âmbitos da: integração produtiva; ciência, tecnologia e inovação; comunicação e informação; integração da infraestrutura de transportes; livre circulação de bens e serviços; e livre circulação de pessoas. Pretende-se, portanto, promover um exercício acadêmico que possa subsidiar os trabalhos conduzidos no âmbito do GAN, apontando alternativas de integração e complementariedade produtiva entre os dois países.

O desenvolvimento do presente estudo se justifica pela importância que o tema apresenta na atualidade, uma vez que o estabelecimento de um novo paradigma na relação Brasil-Uruguai não apenas possibilita a solução de velhos obstáculos comerciais entre os dois países, mas também estimula os demais integrantes do Mercosul a avançarem no processo de integração do bloco. Ressalta-se que essa integração tem caminhado de forma mais lenta que a pretendida quando da criação do bloco, o que acaba por perpetrar uma paralisia institucional e política, que deve ser superada para se atingir a tão desejada integração.

A fim de se investigar o comércio de serviços entre Brasil e Uruguai, inicialmente, discorrer-se-á sobre a regulação internacional do comércio de serviços, tanto no âmbito multilateral (por meio do General Agreement on Trade in Services - GATS) quanto no regional (Mercado Comum do Sul - Mercosul). Em seguida, promover-se-á um estudo sobre a realidade do comércio de serviços entre Brasil e Uruguai, trazendo-se à baila dados 
concretos de ambos os países. No terceiro momento, analisar-se-á o setor de tecnologia da informação e comunicação (TIC) e softwares, investigando-se qual sua relevância e participação no comércio entre os dois países e como e em que medida ele pode se caracterizar como elemento-chave para o aprofundamento das relações comerciais entre os dois países. A metodologia adotada no desenvolvimento da pesquisa consistiu-se como teórica, bibliográfica, descritiva e exploratória.

\section{A RegulamentaÇÃo INTERNACIONAL DE SERVIÇOS}

Durante a vigência do Acordo Geral de sobre Tarifas e Comércio (General Agreement on Tariffs and Trade - GATT), as negociações no sistema multilateral do comércio focaram-se na liberalização do comércio de bens, permanecendo a temática dos serviços apenas no âmbito doméstico dos Estados. Essa realidade alterou-se, somente, com a emergência da Rodada Uruguai (1986-1994), em que o tema foi incluído nas negociações, resultando no marco legal internacional do Acordo Geral sobre Comércio de Serviços (General Agreement on Trade in Services - GATS). Mais flexível que o GATT, o GATS não obriga os membros a assumirem compromissos mínimos (benchmarks), o que significa a não obrigatoriedade de vinculação a um mínimo de setores, subsetores e modos de prestação objetos de compromisso, e uma maior margem de manobra para que se vincule aos compromissos consoantes aos seus interesses políticos e econômicos.

Por meio de negociações progressivas, o GATS se utiliza de listas positivas para identificar os compromissos assumidos em cada setor, subsetor e modo de prestação de serviços. Há, também, a possibilidade de se instituir uma lista negativa, em que os Membros identificam os setores que não estão cobertos pelo compromisso e aqueles compromissos que não constam na lista automaticamente encontram-se liberalizados, exceto se incluídos expressamente, em um anexo, para estabelecer as condições de acesso a mercados e tratamento nacional ${ }^{1}$.

1 CELLI JÚNIOR, Umberto. Os acordos de serviços (GATS) e de investimentos (TRIMS) na OMC: espaço para políticas de desenvolvimento. Centro Brasileiro de Relaçoes Internacionais, Ano 2, v. 1, p. 126, 2007.
Segundo Umberto Celli Júnior, no GATS, há a prevalência de um modelo híbrido, de lista positiva, com uma escolha voluntária e positiva dos setores e subsetores e modos de prestação assumidos pelo governo, e de lista negativa, em que os Membros identificam os setores que não estão cobertos pelo compromisso, e aqueles compromissos que não constam na lista, automaticamente, encontram-se liberalizados, exceto se incluídos, expressamente, em um anexo, para estabelecer as condições de acesso a mercados e tratamento nacional $^{2}$, para identificar as limitações de acesso a mercados e tratamento nacional quanto aos compromissos previstos nas listas ${ }^{3}$.

Ademais, o GATS dispõe, em seu art. I, 2, quatro modos de prestação internacional de serviços: Modo 1 prestação transfronteiriça de serviços (cross-bordersupply), do território de um Membro ao território de qualquer outro Membro, sem a transposição de qualquer profissional na prestação; Modo 2 - consumo no exterior (consumption abroad), no território de um Membro aos consumidores de serviços de qualquer outro Membro; Modo 3 - presença comercial, em que o prestador de serviços de um Membro realiza o serviço por meio da presença comercial no território de qualquer outro Membro; e Modo 4 - presença de pessoas físicas, em que o prestador de serviços de um Membro realiza os serviços pela presença de pessoas físicas de um Membro no território de outro Membro4.

Nesse perspectiva, em razão da complexidade para se estabelecer uma única definição do que se tratam os serviços, em razão de sua amplitude, os negociadores do GATS optaram por dispor onze subsetores bem definidos (e um residual). São eles: (i) serviços de negócios ou empresariais; (ii) serviços de comunicação; (iii) serviços de construção; (iv) serviços de distribuição; (v) serviços educacionais; (vi) serviços ambientais; (vii) serviços financeiros; (viii) serviços relacionados à saúde e serviços sociais; (ix) serviços de turismo e relacionados a viagens; (x) serviços de recreação, serviços culturais

2 CELLI JÚNIOR, Umberto. Os acordos de serviços (GATS) e de investimentos (TRIMS) na OMC: espaço para políticas de desenvolvimento. Centro Brasileiro de Relações Internacionais, Ano 2, v. 1, p. 126, 2007.

3 CELLI JÚNIOR, Umberto. Os acordos de serviços (GATS) e de investimentos (TRIMS) na OMC: espaço para políticas de desenvolvimento. Centro Brasileiro de Relações Internacionais, Ano 2, v. 1, p. 126, 2007.

4 CELLI JÚNIOR, Umberto. Comércio de serviços na OMC: liberalização, condições e desafios. Curitiba: Juruá, 2009. p. 87. 
e esportivos; (xi) serviços de transporte; e (xii) outros serviços.

Grupos de trabalho instituídos no âmbito da OMC 5 também entendem que o GATS se apresenta como o Acordo mais aplicável à regulação do comércio eletrônico, haja vista que as transações realizadas na internet constituem, em sua grande maioria, em uma prestação de serviço ${ }^{6}$. Além disso, destaca-se que todos os setores podem ser alvo de negociações pelo GATS, com exceção de serviços governamentais ${ }^{7}$.

Dentre as demais previsões contidas no acordo, estão os principais princípios norteadores do GATS, previstos nos artigos II e III, quais sejam o da cláusula da nação mais favorecida e o da transparência, ambos replicados do GATT e aplicados a todos os setores ${ }^{8}$. Além disso, existem os compromissos de acesso a mercados, em que os Membros devem afastar barreiras que dificultem o comércio de serviços, tais como requisitos regulatórios ou restrições quantitativas, além do tratamento nacional, para que não haja discriminação dos prestadores de serviços estrangeiros em comparação aos nacionais nos respectivos setores previstos nas listas. Segundo o art. VI do GATS, os compromissos acordados não devem ser implementados de modo a restringir o policy space de seus Membros, comprometendo a adoção de políticas públicas ou de desenvolvimento.

No contexto da Rodada Uruguai, destaca-se que Brasil e Uruguai também atuaram nas negociações de serviços e consolidaram seus compromissos. No caso do Brasil

5 Para entender o desenvolvimento do comércio eletrônico mundialmente, a OMC realizou diversas cooperações e estudos com outras organizações internacionais, como Organização para Cooperação e Desenvolvimento Econômico (OCDE), Comissão das Nações Unidas para o Direito do Comércio Internacional (UNICITRAL) e Organização Mundial da Propriedade Intelectual (OMPI).

6 ALVES, Gleisse Ribeiro. O Acordo GATS e sua aplicação aos serviços do comércio eletrônico. Revista de Direito Internacional, Brasília, v. 12, n. 2, p. 321-336, 2014.

7 CELLI JÚNIOR, Umberto. Comércio de serviços na OMC: liberalização, condições e desafios. Curitiba: Juruá, 2009. p. 86.

8 Segundo o princípio da nação mais favorecida qualquer vantagem, favor, imunidade ou privilégio concedido por uma Parte contratante em relação a um produto originário de ou destinado a qualquer outro país, será imediata e incondicionalmente estendido ao produtor similar, originário do território de cada uma das outras Partes contratantes ou ao mesmo destinado. Já o princípio da transparência corresponde à publicação e administração dos regulamentos de comércio para o conhecimento e a publicidade de leis, restrições, proibições, padrões, recomendações e qualquer outra forma de regulamentação referente aos produtos e às relações comerciais celebradas entre as Partes. foram realizados compromissos horizontais, com aspectos regulatórios aplicáveis a todos os setores de serviços, principalmente medidas dos Modos 3 e 4, sobre movimento de pessoas físicas e investimento estrangeiro direto. A lista, também, inclui medidas relativas a subsídios, porquanto essas se referem a todos os modos de prestação, e compromissos setoriais abrangendo somente 7 dos 11 setores classificados na lista da OMC, tais como: serviços prestados às empresas, comunicações, construção, distribuição, serviços financeiros, turismo e transportes (para nenhum desses setores o país incluiu subsetores) $)^{9}$.

Após a Rodada Uruguai, o tema, também, passou a ser paulatinamente incluído nos acordos regionais de comércio $^{10}$. De forma generalizada, os acordos regionais estabelecem um grau de comprometimento muito maior do que os assumidos no GATS, porquanto as normativas regionais têm evoluído mais intensamente sobre o que já está previsto na OMC, configurando-se como um acordo OMC plus ${ }^{11}$.

Em nível regional, destaca-se o estabelecido pelo Mercosul, que possui dentre seu escopo principal a livre circulação de serviços e a coordenação regional das políticas setoriais de serviços como um dos aspectos mais relevantes de seu processo de integração (art. $1^{\circ}$ do Tratado de Assunção). Após várias negociações sobre o tema, foi firmado o Protocolo de Serviços de Montevidéu sobre o Comércio de Serviços ${ }^{12}$ em 1997, com vistas à liberalização de serviços.

Nesse contexto, cogitou-se expandir a união aduaneira também para serviços (não apenas bens), por meio de uma política comercial única em relação a terceiros países. Contudo, pela heterogeneidade dos setores existentes e da elevada incidência de regulamentações sobre o tema pelos países membros do Mercosul, somados à experiência da europeia, que, no período analisado,

9 MARCONINI, Mário. OMC, acordos regionais e o comércio de serviços: normativa internacional e interesse brasileiro. São Paulo: Aduaneiras, 2003. p. 234-237.

10 ROY, Martin; MARCHETTI, Juan; LIM, Hoe. Services liberalization in the new generation of preferential trade agreements: how much further than GATS? WTO working-paper. 2006. Disponível em: <https://www.wto.org/ENGLISH/res_e/reser_e/ersd200607_e. pdf>. Acesso em: 01 maio 2015.

11 HORN, H.; MAVROIDIS, P.; SAPIR, A. Beyond the WTO? An anatomy of EU and US preferential trade agreements. Bruegel Blueprint Series, v. 7, 2009.

12 Aprovado pela Decisão Conselho Mercado Comum (CMC) $\mathrm{n}^{\circ}$ 13/97, o Protocolo de Montevidéu foi internalizado pelo Brasil sob o Decreto ${ }^{\circ}$ 6.480, de 11 de junho de 2008 e pelo Uruguai, pela Ley $\mathrm{n}^{\circ} 17.885$ de 2004. 
ainda não tinha alcançado a livre circulação de serviços, tal pretensão foi afastada da agenda negociadora ${ }^{13}$. Segundo Petros Mavroidis, o Protocolo de Montevidéu trata-se de um contrato de integração negativa ${ }^{14}$, pois objetiva eliminar a discriminação, sem interferir no policy space dos Estados-Membros do Mercosul e por consistir em um processo de integração cuja finalidade principal trata-se da liberalização do setor de serviços ${ }^{15}$.

Nessa esfera evolutiva, ressalta-se que o Protocolo de Serviços do Mercosul estabeleceu o mecanismo de compromissos por meio de negociações específicas de acesso a mercados e de tratamento nacional, embasado em listas positivas, classificadas como estratégia gradual de liberalização, possuindo maior flexibilidade. Ressalta-se que esse mecanismo é, claramente, inspirado no GATS, tratando-se de acordo-quadro, com anexos setoriais sobre serviços financeiros, transporte terrestre, aquaviário e aéreo, e quanto ao movimento temporário de pessoas físicas foram firmadas listas individuais de compromissos específicos por Estado, negociados com o Protocolo, também contendo aquelas negociadas de início (incluídas na Decisão $n^{\circ}$ 09/98) e as que resultaram de negociações provenientes durante as rodadas.

Em 1998, foi criado o Grupo de Serviços (GS) do Mercosul, que tem a função de fomentar a implementação do Protocolo de Montevidéu por meio de rodadas de negociação sobre a matéria, permitindo um aumento progressivo dos compromissos assumidos pelos Estados do Mercosul. No mesmo ano, a Resolução Grupo Mercado Comum (GMC) no 73/98 instituiu regras sobre o funcionamento deste GS e sobre as rodadas de liberalização, estabelecendo critérios de transparência a serem aplicados na troca de ofertas e pedidos.

Salienta-se que cada rodada teve importância na evolução do tratamento da matéria no bloco, porém, ao se efetuar um balanço sobre os avanços, nota-se que estes ainda estão aquém do pretendido para que se siga com vigor e direção à liberalização. As cinco primeiras rodadas foram realizadas sem que o Protocolo entrasse em vigor, porém, isso não afasta os compromissos fir-

13 ARSLANIAN NETO, Michel. A liberalização do comércio de serviços do Mercosul. Brasília: FUNAG, 2010. p. 100.

14 No original, Mavroidis utiliza a expressão "negative integration contract". Cf. MAVROIDIS, 2006, apud GARI, Gabriel. The liberalization of Trade in Services in Mercosur. Centre for Commercial Law Studies. Londres: University of London, 2008. p. 41.

15 ARSLANIAN NETO, Michel. A liberalização do comércio de serviços do Mercosul. Brasília: FUNAG, 2010. p. 103. mados para o processo de liberalização de serviços no bloco. Ocorre que o intervalo até a entrada em vigor da Resolução GMC no 36/00 demonstra que o GS não se encontra exatamente na lista de prioridades do bloco. Os principais desafios atinentes à liberalização de serviços no Mercosul permanecem sendo a redução e eliminação das restrições sobre o setor de serviços, já que as Rodadas Negociadoras até o momento tão somente consolidam as restrições vigentes, com o compromisso de não estabelecerem restrições ainda mais restritivas que as já previstas nas listas pelos Estados Partes ${ }^{16}$.

Importante destacar que no Mercosul todos os setores foram objeto de compromisso, alguns deles mais profundos, outros mais superficiais. Ademais, enquanto na OMC predominam em média os compromissos do Modo 3 (presença comercial), no Mercosul também incidem os de Modos 1 (prestação transfronteiriça de serviços) e 2 (consumo no exterior). Mesmo que não tenha havido tantos avanços nos compromissos no Modo 4 (presença de pessoas físicas) e em matéria de presença comercial, os países do Mercosul evoluíram, significativamente, nos compromissos de natureza horizontal aqueles aplicados a todos os setores - e se acrescentou a categoria de pessoas físicas, instituindo-se um menor número de limitações à entrada e permanência temporária dos prestadores de serviços.

Outro fator que colabora para a maior liberalização do Mercosul é a existência de compromissos sem res-

16 Nesse caso, conforme levantamento realizado pelo GS sobre a origem legal das inscrições em lista, destaca-se que na XXIV Reunião Ordinária do GS (MERCOSUL/GMC/GS/ATA No 03/04 - Anexo IV), a maioria das restrições não são de ordem infralegal e, portanto, não podem ser facilmente levantadas pelo Poder Executivo, devendo sê-lo feito pelo Poder Legislativo, o que implica em maior demora, bem como dificuldade, em decorrência de vedações de ordem constitucional. O Brasil veda em sua Carta Magna a participação direta ou indireta de empresas estrangeiras na

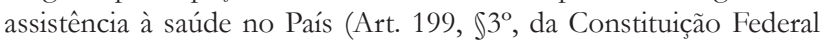
do Brasil), restringe a propriedade de empresa jornalística e de radiofusão sonora e de sons e imagens privativamente aos brasileiros natos ou naturalizados há mais de dez anos ou às pessoas jurídicas constituídas sob as leis brasileiras e que tenham sede no País (Art. 222) e as jazidas, em lavra ou não, e demais recursos minerais e os potenciais de energia hidráulica, para efeito de exploração ou aproveitamento, como pertencentes à União (Art. 176). Ainda, limita-se legalmente à autorização presidencial a instalação de bancos estrangeiros em território nacional, cuja alteração requer aprovação de Lei Complementar, assim como cabe ao Executivo a prerrogativa de estabelecer limites à participação estrangeira no capital de empresas prestadoras de serviços de telecomunicações, que para ser modificada requer derrogação da Lei Geral de Telecomunicações (Lei n ${ }^{\circ}$ 9472/97). 
trições. Dentre eles, se destaca os serviços profissionais (exceto pelo Paraguai), informática, outros serviços prestados às empresas (consultoria, administração, oferta de recursos humanos, serviços de convenções etc.), construção, distribuição (comércio atacadista e varejo) e turismo. Ademais, cumpre ressaltar que não há tantas limitações em vários dos demais compromissos assumidos como no plano multilateral do comércio.

Apesar disso, apenas, em 2005 o Protocolo de Montevidéu entrou em vigor, com o prazo de dez anos para completar o Programa de Liberalização de serviços regionalmente (que estava programado para se esgotar em 2015). Até o momento, foram concluídas sete Rodadas Negociadoras no âmbito do comércio de serviços, que se traduziram em listas de compromissos, em que apenas as seis primeiras já foram aprovadas pelo legislativo brasileiro e possuem Decretos Legislativos que internalizam seus compromissos ${ }^{17}$. Apesar de apenas a primeira lista de compromissos encontrar-se em vigor, normas comuns sobre serviços também foram aprovadas.

Nesse aspecto, critica-se que as negociações em serviços não têm provocado amplo acesso a mercados, se comparadas aos cortes tarifários para bens, tendo o condão de apenas estabelecer compromissos de não incorporação de restrições futuras ao setor. Ressalta-se que até hoje o Mercosul nunca deixou de ser uma união aduaneira em construção, perfurada constantemente por exceções nacionais a regras comuns, sendo, portanto, necessário repensar a atual situação em que essa iniciativa de integração regional se encontra ${ }^{18}$. O Mercosul deve se mostrar adaptável a "um processo evolutivo cujos patamares vêm sendo erguidos de acordo com as necessidades que emanam do bloco" ${ }^{19}$.

17 A última rodada internalizada pelo Brasil foi a VI Rodada, pelo Decreto Legislativo $n^{\circ}$ 984/2009. O entendimento do Congresso Nacional, na Comissão de Relações Exteriores e de Defesa Nacional sobre a não internalização das III, IV e V Rodadas, em Reunião Deliberativa Ordinária de 27/05/09, é de que como as disposições da Decisão CMC n 01/06 correspondentes a VI Rodada revogam as disposições das Rodadas anteriores, não houve necessidade de aprovação destas. Quanto à VII Rodada, não há registro de mensagem do Poder Executivo para o Poder Legislativo para que se tramite a internalização da Decisão CMC n $n^{\circ} 21 / 09$. Os compromissos posteriores ainda não estão em vigor, pois dependem da internalização em todos os países do Mercosul.

18 ALMEIDA, Paulo Roberto de. Brazilian Trade Policy in Historical Perspective: constant features, erractic behavior. Revista de Direito Internacional, Brasília, v. 10, n. 1, p. 11-23, 2013.

19 FEIJÓ, Camila de Freitas. O Atual Sistema de Solução de Controvérsias do Mercosul: rumo à consolidação de um tribunal regional. Revista de Direito Internacional, Brasília, v. 9, n. 1, p. 69-89,
Apesar da existência de compromissos em nível regional, destaca-se que o mundo contemporâneo passa por uma fase de mudanças quanto à liberalização de serviços. Desde 2013, vislumbram-se esforços para a negociação de um Acordo Plurilateral sobre Comércio em Serviços (em inglês, Trade in Services Agreement - TIS A) ${ }^{20}$. Atualmente, 23 países fazem parte das negociações. São eles: Austrália, Canadá, Chile, Colômbia, Costa Rica, Estados Unidos, Hong Kong, Islândia, Israel, Japão, Liechtenstein, México, Nova Zelândia, Noruega, Paquistão, Panamá, Paraguai, Peru, República da Coreia, Suíça, Taiwan, Turquia, União Europeia (representando seus 28 membros). Ressalta-se que esses países concentram $70 \%$ do comércio internacional de serviços ${ }^{21}$. O Uruguai integrava as negociações, contudo, em setembro de 2015, anunciou seu afastamento.

O principal objetivo do TISA ${ }^{22}$ consiste em liberalizar ainda mais o setor de serviços, de forma a driblar a paralisia das tratativas no sistema multilateral da OMC e dos sistemas regionais, e atrair nações que pretendem avançar as negociações no tema. Esse acordo se revela audacioso e pretende englobar todos os setores de serviços, tais como: serviços financeiros; serviços de tecnologia da informação (incluindo telecomunicação e e-commerce); serviços profissionais; serviços de transporte marítimos; serviços de transporte aéreo; serviços de entrega; serviços em energia; entrada temporária de pessoas para negócios; e compras governamentais. Por fim, temas como acesso a mercados e as regras de regulação doméstica também serão incluídos, para que não atuem como barreiras não tarifárias ao comércio ao mesmo tempo que novas disciplinas em serviços serão instituídas.

\section{O comércio de SERVIços de Brasil e URUGUAI}

Nos últimos anos, o Brasil tem participado, ativamente, do comércio mundial de serviços. Entre 2009 a 2014, as exportações de serviços mundiais cresceram $38,2 \%$, so-

jan. /jun. 2012. p. 71.

20 Optou-se pela utilização da sigla em inglês Trade in Services Agreement (TIS A) por ser a mais utilizada.

21 MARCHETTI, Juan; ROY, Martin. The TISA Initiative: an overview of market access issues. Journal of World Trade, v. 48, n. 4, p. 683-728, 2014.

22 Ressalta-se que, por ser um acordo plurilateral, não é necessária a aprovação de todos os Membros a todas as previsões do acordo. 
mando, em 2014, US\$ 4,86 trilhões. Em 2014, os EUA lideraram as exportações mundiais de serviços com US $\$ 685,6$ bilhões, acompanhado pelo Reino Unido com US $\$ 329,0$ bilhões e Alemanha com US $\$ 267,2$ bilhões. O Brasil ocupou apenas a $31^{a}$ posição com US $\$ 39,8$ bilhões. Quanto às importações mundiais de serviços no mesmo ano, estas totalizaram US\$ 4,74 trilhões e os EUA também seguiram à dianteira, com US $\$ 454,5$ bilhões, seguidos por China, com US \$ 382,1 bilhões, e Alemanha, com US \$326,8 bilhões. O Brasil restou na $17^{\mathrm{a}}$ posição, com US $\$ 87$ bilhões $^{23}$.

Em 2014, segundo dados do Sistema Integrado de Comércio Exterior de Serviços, Intangíveis e Outras Operações que Produzam Variações no Patrimônio (SISCOSERV) ${ }^{24}$, as exportações de serviços brasileiros registradas no SISCOSERV foram de US $\$ 20,8$ bilhões. Os cinco principais mercados para os quais o Brasil exportou serviços foram: (i) Estados Unidos (US\$ 6,11 bilhões); (ii) Países Baixos (US\$1,72 bilhão); (iii) Suíça (US\$ 1,26 bilhão); (iv) Alemanha (US\$ 1,22 bilhão) e (v) Reino Unido (US\$ 957 milhões). Juntas, essas economias representaram $54,2 \%$ de todas as exportações de serviços registradas durante todo o período.

23 BRASIL. Ministérios do Desenvolvimento, Indústria e Comércio Exterior. Serviços: Panorama do Comércio Internacional Dados de 2014. MDIC. 2015. Disponível em: <http://www.mdic. gov.br//arquivos/dwnl_1431972666.pdf>. Acesso em: 22 jun. 2015.

24 O SISCOSERV possui elevada granularidade, sendo referenciado por nomenclatura com mais de 900 serviços catalogados. Ademais, o sistema captura, por meio dos registros de venda e aquisição de serviços (RVS e RAS, respectivamente), o fluxo comercial de serviços e intangíveis entre o Brasil e o resto do mundo. O fluxo financeiro decorrente destas operações é capturado pelos registros de faturamento $(\mathrm{RF})$, decorrência das vendas, e pagamento (RP), decorrência das aquisições de serviços e intangíveis. A atual divulgação de dados contemplará o fluxo comercial, ou seja, os registros de venda e aquisição de serviços e intangíveis (RVS e RAS). O SISCOSERV, por não manter correlação com o fechamento de câmbio, captura, inclusive, as operações de comércio exterior de serviços realizadas com recursos mantidos no exterior. $\mathrm{O}$ universo de pessoas físicas e jurídicas obrigadas ao registro no SISCOSERV, e a classificação dos serviços e intangíveis por meio da NBS, distingue os dados extraídos do SISCOSERV da conta de serviços do Balanço de Pagamentos, compilado pelo Banco Central do Brasil conforme a sexta edição do Manual de Balanço de Pagamentos e Posição Internacional de Investimentos do FMI (BPM6), e apoiado nas informações dos contratos de câmbio. As diferenças em termos de metodologia e fontes de dados não permitem, portanto, plena comparabilidade entre os dois conjuntos de informação. Para mais informações sobre o Siscoserv: <http://www.mdic. gov.br/ sitio $/$ interna/interna.php?area $=4 \&$ menu $=2234>$. Cf. BRASIL. Ministérios do Desenvolvimento, Indústria e Comércio Exterior. Notas Metodológicas dos dados do SISCOSERV. MDIC. 2016. Disponível em: <http://www.mdic.gov.br//sitio/interna/interna. php?area $=4 \&$ menu=4998> . Acesso em: 07 jan. 2016.
Quanto às importações, de acordo com o SISCOSERV, o Brasil adquiriu US $\$ 48,5$ bilhões de serviços estrangeiros. Ademais, segundo o Panorama do Comércio Exterior de Serviços, em 2014, o Brasil importou serviços principalmente de: (i) Estados Unidos (US\$ 13,1 bilhões); (ii) Países Baixos (US\$12,0 bilhões); (iii) Alemanha (US\$2,49 bilhões); (iv) Reino Unido (US\$ 2,29 bilhões) e (v) Noruega (US\$1,82 bilhão). Esses mercados fornecedores representam $65,7 \%$ do total da importação de serviços feita pelo Brasil, conforme registrado pelo SISCOSERV 25 .

Já no que tange ao Uruguai, este tem passado por um processo de abertura econômica intensa nas últimas duas décadas, se tornando um polo exportador de serviços na América do Sul. Entre 2002-2012, a comercialização de serviços tradicionais, como transporte e turismo elevou-se em $16 \%$, e nos serviços não tradicionais, como serviços financeiros, seguros, de tecnologia da informação e comunicação (TIC), de construção, dentre outros, houve um aumento de $24 \%$. Os serviços não tradicionais somam US $\$ 1,341$ milhão e representaram $32 \%$ das exportações de serviços em 2012, mais que o dobro das exportações totais de serviços computadas nos anos 2000, que eram de $15 \%{ }^{26}$.

Em 2013, o Uruguai alcançou um crescimento real de 3,5\%, e seu PIB nominal foi de US\$ 57,1 bilhões, sendo que grande parte do PIB é canalizado através do setor de serviços, 71,8\% do PIB total, enquanto a indústria abrange $20,9 \%$ e a agricultura por $7,4 \%{ }^{27}$.

Os serviços globais de exportação também abrangem serviços não tradicionais e se originam da decisão da empresa de deslocar atividade ou processo que antes era realizado em território nacional, para o estrangeiro. Os serviços globais mais exportados pelo Uruguai são os de assessoramento profissional, TICs e os vinculados

25 BRASIL. Ministérios do Desenvolvimento, Indústria e Comércio Exterior. Serviços: Panorama do Comércio Internacional Dados de 2014. MDIC. 2015. Disponível em: <http://www.mdic. gov.br//arquivos/dwnl_1431972666.pdf>. Acesso em: 22 jun. 2015.

26 INSTITUTO DE PROMOCÍON DE INVERSIONES Y EXPORTACIONES DE BIENES Y SERVICIOS. Servicios globales de exportación: Oportunidades de inversión en Uruguay. URUGUAY XXI. 2013. Disponível em: <http://www.smartservices.uy/ innovaportal/v/754/7/innova.front/reportes.html>. Acesso em: 19 fev. 2015.

27 BRASIL. Ministérios do Desenvolvimento, Indústria e Comércio Exterior. Perfil dos negócios em serviços: Brasil e os países da copa 2014. MDIC. 2014. Disponível em: <http://www.mdic.gov. br/arquivos/dwnl_1407760950.pdf>. Acesso em: 27 abr. 2015. 
à centralização de atividades de empresas globais (Centros de Serviços Compartilhados).

As principais localidades que exportam serviços no território uruguaio são as zonas francas de Aguada Park e WTC Free Zone, em Montevidéu, próximas ao Porto de Montevidéu. Dentre os principais subserviços oferecidos, com 95\% de ocupação, salientam-se os serviços de desenvolvimento de software, call centers, processos de negócios terceirizados (BPO) e serviços compartilhados, serviços financeiros, serviços profissionais e trading (agrobusiness, têxtil, energia e navegação), todos esses direcionados à exportação. As principais empresas ali instaladas são: APAC CustomerServides, Globant, Mercado Libre, CorporaciónNavios, TravelLeaders, Banco Itaú, Teyma y Sabre Holdings, dentre outras. Em WTC Free Zone, prevalecem serviços de consultoria (três dentre as quatro maiores do mundo), serviços financeiros e estudos profissionais, entre outros. Ali estão instaladas empresas como: Burger King, PwC, Deloitte, TCI Delivery Center, Estudios Energéticos Consultores, CatalentUruguay, Baker Tilly, Latinbroker, Towers Watson, MVD Consulting, Bragard\&Durán, Galante \& Martins Internacional, Trillonario.com, Contract Global Services, dentre outros ${ }^{28}$.

Atualmente, o comércio de serviços entre Brasil e Uruguai tem se mostrado relevante na relação bilateral entre as duas nações. Segundo relatório Serviços - Perfil dos Negócios Bilaterais 2014, do MDIC, em 2014, o Uruguai restava-se como o $19^{\circ}$ país de aquisição das exportações brasileiras de serviços (US\$268 milhões), com uma participação de $1,3 \%$, e como $10^{\circ}$ destino dos pagamentos das importações brasileiras de serviços (US\$ 912 milhões), com uma participação de 1,9\%, e déficit de US\$ - 643,758 milhões $^{29}$. Em relação aos principais serviços exportados pelo Brasil ao Uruguai e os principais serviços adquiridos pelo Brasil do Uruguai, destacam-se:

28 INSTITUTO DE PROMOCÍON DE INVERSIONES Y EXPORTACIONES DE BIENES Y SERVICIOS. Servicios globales de exportación: Oportunidades de inversión en Uruguay. URUGUAY XXI. 2013. Disponível em: <http://www.smartservices.uy/ innovaportal/v/754/7/innova.front/reportes.html>. Acesso em: 19 fev. 2015.

29 "Além disso, no Brasil há 1.511 vendedores de serviços para o Uruguai, ao passo que possui 1.245 adquirentes de serviços uruguaios. A corrente de comércio de serviços entre os dois países é de US\$ 1.179.888 mi”. BRASIL. Ministérios do Desenvolvimento, Indústria e Comércio Exterior. Serviços: Perfil dos negócios bilaterais 2014. MDIC. 2015b. Disponível em: <http://www.mdic.gov.br// arquivos/dwnl_1432054087.pdf>. Acesso em: 22 jun. 2015.
Tabela 1 - Vendas/Exportações do Brasil para o Uruguai por setor de serviços $(2014)^{30}$

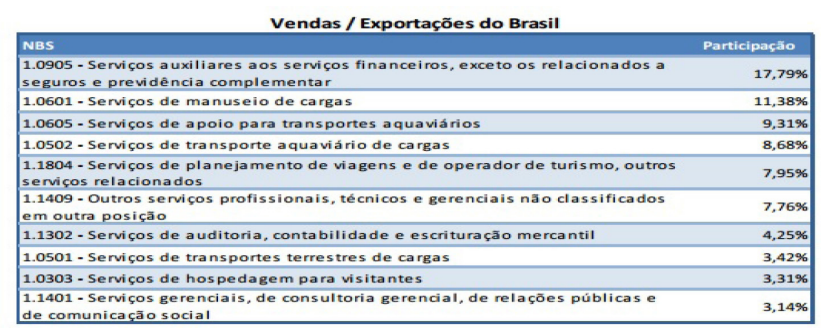

Tabela 2 - Aquisições/Importações do Uruguai pelo Brasil por setor de serviços (2014) ${ }^{31}$

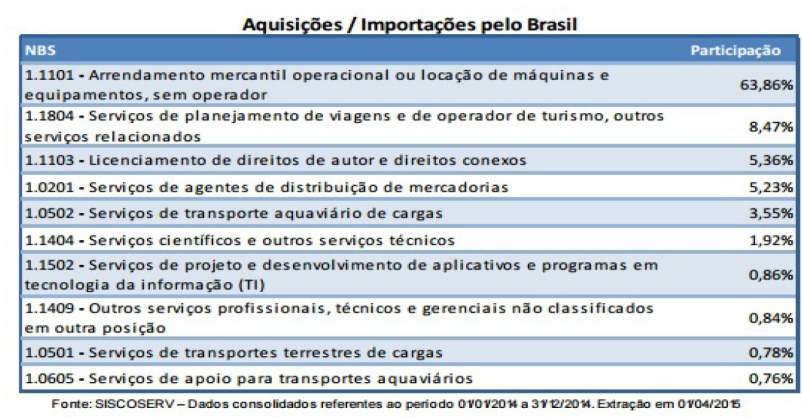

Analisados os dados do comércio de serviços de Brasil e Uruguai, tanto no que se refere às exportações quanto às importações, bem como aos índices presentes no âmbito do Mercosul, tem-se que o comércio bilateral entre eles continua deficitário para o Brasil até recentemente. Destaca-se, também, que o setor de tecnologia da informação e comunicação (TIC) encontra-se dentre os principais serviços comercializados entre os dois países. Dessa forma, passa-se à análise desse setor específico, escolhido em razão de sua relevância para o aprofundamento da integração econômica entre Brasil e Uruguai.

\section{O SETOR DE TECNOLOGIA DA INFORMAÇÃo E COMUNICAÇÃO (TIC) E SOFTWARES}

O presente artigo optou por examinar o setor de tecnologia da informação e comunicação (TIC) e softwares. Isto se deu, principalmente, devido à sua importância para a promoção da integração produtiva e

30 BRASIL. Ministérios do Desenvolvimento, Indústria e Comércio Exterior. Serviços: Perfil dos negócios bilaterais 2014. MDIC. 2015b. Disponível em: <http://www.mdic.gov.br// arquivos/dwnl_1432054087.pdf>. Acesso em: 22 jun. 2015.

31 BRASIL. Ministérios do Desenvolvimento, Indústria e Comércio Exterior. Serviços: Perfil dos negócios bilaterais 2014. MDIC. 2015b. Disponível em: <http://www.mdic.gov.br// arquivos/dwnl_1432054087.pdf>. Acesso em: 22 jun. 2015. 
para a formação de cadeias globais de valor e, no âmbito regional, em razão de serem essenciais para o desenvolvimento das economias de Brasil e Uruguai. Assim, pretende-se trazer à baila os principais dados econômicos e as regulamentações existentes sobre este setor. Em seguida, serão examinadas as questões e possibilidades que se colocam para um aprofundamento produtivo do setor nesses dois países.

\subsection{Análise Regulatória e Iniciativas de Brasil e Uruguai}

O setor de serviços no Brasil possui um forte dinamismo no setor de Tecnologia da Informação e Comunicação (TIC) e Softwares. O setor de TIC compõe cerca de 5\% do PIB brasileiro e vem crescendo em um ritmo intenso, tendo movimentado US $\$ 169$ bilhões em 2012. Nesse ano, o Brasil se consolidou como o quarto maior mercado de TIC no mundo. As exportações desse tipo de serviços pelo Brasil, em 2012, atingiram um montante considerável de US $\$ 2,48$ bilhões de dólares, dos quais os softwares foram responsáveis por US\$ 61 milhões de dólares ${ }^{32}$.

O Brasil possui um arcabouço regulatório favorável à proliferação da área de TIC. A Lei Federal n ${ }^{\circ}$ 11.196/05 estabelece o Regime Especial de Tributação para a Plataforma de Exportação de Serviços de Tecnologia de Informação (mais conhecido como REPES). Essa regulação beneficia, principalmente, as empresas exportadoras do setor, com a suspensão da exigência de Contribuição PIS/PASEP ${ }^{33}$ e do Cofins $^{34}$ na venda ou

32 INSTITUTO DE PROMOCÍON DE INVERSIONES Y EXPORTACIONES DE BIENES Y SERVICIOS. Servicios globales de exportación: Oportunidades de inversión en Uruguay. URUGUAY XXI. 2013. Disponível em: <http://www.smartservices.uy/ innovaportal/v/754/7/innova.front/reportes.html>. Acesso em: 19 fev. 2015

33 O Programa de Integração Social (PIS) e o Programa do Patrimônio do Servidor Público (PASEP) constituem contribuições sociais de caráter tributário devidas pelas empresas. Elas foram instituídas pela Constituição Federal de 1988 em seu Artigo 239 e regulamentadas, respectivamente, pela Lei Complementar $n^{\circ} 7$, de 7 de Setembro de 1970 e pela Lei Complementar $n^{\circ}$ 8, de 3 de dezembro de 1970. Eles têm por objetivo financiar o programa de seguro desemprego .

34 A Contribuição para Financiamento da Seguridade Social (COFINS) caracteriza-se como uma contribuição social de natureza tributária voltada ao financiamento da Seguridade Social: Previdência Social, Assistência Social e Saúde Pública. Ela foi instituída pela Constituição Federal de 1988 sem eu artigo 195, alínea b, sendo posteriormente regulamentada pelas Lei Complementar $n^{\circ} 70$, de 30 de dezembro de 1991, Lei no 9.718, de 27 de novembro de 1988 e importação de bens e serviços voltados ao desenvolvimento de softwares no Brasil.

Outro estímulo relevante consiste no Plano TI Maior lançado em 2012. Esse marco regulatório beneficia projetos de software e serviços de inovação tecnológica em $\mathrm{R} \$ 500$ milhões de reais (previu-se a concessão até 2015), por meio de incentivos de crédito, bolsas de formação em ciência e tecnologia, melhorias na infraestrutura, investimentos em pesquisa e desenvolvimento e, por fim, renúncia fiscal. Essa iniciativa pretende, também, incentivar start-ups, que vêm contribuindo de forma relevante para a inovação do setor, reservando $\mathrm{R} \$$ 40 milhões do total para investimentos nessas empresas (por meio de aceleradoras).

Destaca-se, também, a iniciativa do Estado de Pernambuco ao criar o Porto Digital na parte histórica da cidade de Recife. O projeto se apresenta como um dos principais parques tecnológicos e ambientes de inovação do Brasil, concentrando-se no desenvolvimento de atividades do setor de softwares e serviços de tecnologia da informação e comunicação (TIC), como games, multimídia, cine-vídeo-animação e música ${ }^{35}$. Advinda de uma parceria entre governo, academia e empresa, o porto digital abriga atualmente 250 empresas, organizações de fomento e órgãos governamentais que perfazem cerca de 7.100 trabalhadores. Dentre os benefícios oferecidos para a atração de empresas, destacam-se a redução do imposto sobre serviços de qualquer natureza (ISS) ${ }^{36}$; isenção do imposto predial territorial urbano $(\text { IPTU })^{37}$ e redução do imposto de renda ${ }^{3839}$.

No Uruguai, a produção e comercialização do setor de TICs e de softwares são cada vez mais dinâmicas e voltadas à exportação. Nos anos 1990, esse setor exportava aproximadamente US\$ 4 milhões, tendo se elevado consideravelmente na década seguinte para US\$104,48 mi-

Lei no 10.833, de 29 de dezembro de 2003.

35 PORTO DIGITAL PARQUE TECNOLÓGICO. O que é o Porto Digital. Disponível em: <http://www.portodigital.org/parque/ o-que-e-o-porto-digital>. Acesso em: 5 Junho 2016.

36 A Prefeitura de Recife concede uma redução de 60\% do ISS que, com esse desconta, passa de $5 \%$ para $2 \%$.

37 A Lei Municipal n 16.290/97 (Recife) concede isenção do IPTU a partir do tipo de reforma realizada no imóvel ocupado.

38 Essa redução do imposto de renda é prevista pelo Decreto $\mathrm{n}^{\circ}$ 4.123, de 26 de Abril de 2002, que define os setores da economia prioritários para o desenvolvimento regional, nas áreas de atuação da extinta SUDENE, e dá outras providências.

39 PORTO DIGITAL PARQUE TECNOLÓGICO. Beneficios. Disponível em: <http://www.portodigital.org/diferenciais/ beneficios>. Acesso em: 5 jun. 2016. 
lhões. Dentre os fatores que determinam essa evolução, pode-se destacar: (i) a presença de recursos humanos talentosos no Uruguai; (ii) líderes empresariais que impulsionaram o desenvolvimento de tecnologia de ponta e capacidades profissionais competitivas; (iii) a existência de alianças e redes de cooperação entre empresas uruguaias e multinacionais estrangeiras, em diferentes mercados, e (iv) a disponibilidade de infraestrutura em matéria de TICs e de softwares ${ }^{40}$.

Dentre os serviços que englobam TICs no Uruguai, destacam-se as empresas que desenvolvem softwares, empresas de consultorias e serviços de informática, internet e dados. Dessas, as duas primeiras são voltadas para a exportação, enquanto a última direciona-se mais para o mercado interno. Destaca-se que, no Uruguai, há a concentração geográfica das empresas que produzem TIC e software em cluster $^{41}$. Aproximadamente, $90 \%$ dessas empresas se localizam no departamento de Montevidéu e no interior elas se encontram em maior presença apenas nos departamentos de Maldonado e Colônia ${ }^{42}$. Assim, o fato de se concentrarem na capital e em uma área privilegiada e com incentivos próprios faz com que o setor evolua bem e em rápida progressão.

A existência de incentivos tributários regulatórios para a área, também, visa à promoção setor. Dentre esses incentivos, destacam-se os respectivos marcos regulatórios: (i) Decreto $n^{\circ} 84 / 99$, que institui a declaração de interesse nacional da atividade de produção de software; (ii) Decreto n $386 / 00$, que prevê a exoneração de pagamento de Imposto ao Valor Agregado (IVA) à exportação de TIC e softwares, o que estimula as expor-

40 GONZÁLEZ, Irene; PITTALUGA, Lucía. El sector de software y servicios informáticos en Uruguay: complementación productiva intra Mercosur en El marco de las estrategias de internacionalización de las empresas uruguayas. Febrero, 2007. Disponível em: <http:// goo.gl/Q2eg6f >. Acesso em: 27 abr. 2015.

41 Em termos industriais, um cluster é uma aglomeração de empresas de portes variados, com presença significativa de pequenas empresas não integradas verticalmente, fabricantes de um mesmo tipo de produto ou produtos similares. Devido à colaboração entre si, elas se tornam mais eficientes. INSTITUTO DE ESTUDOS PARA O DESENVOLVIMENTO INDUSTRIAL. Clusters on Sistemas Locais de Produção e Inovação: identificação, caracterização e medidas de apoio. São Paulo: IEDI, Maio de 2002. Disponível em: <http://www.iedi.org.br/admin/pdf/20030516_clusters.pdf>. Acesso em: 6 jun. 2016.

42 GONZÁLEZ, Irene; PITTALUGA, Lucía. El sector de software y servicios informáticos en Uruguay: complementación productiva intra Mercosur en El marco de las estrategias de internacionalización de las empresas uruguayas. Febrero, 2007. Disponível em: <http:// goo.gl/Q2eg6f >. Acesso em: 27 abr. 2015. tações; (iii) Decreto $n^{\circ} 387 / 00$ e sucessivos, que estabelecem a exoneração do pagamento de Imposto de Renda à produção de softwares; (iv) Decreto n 144/02, que exonera retenções por conceito de Imposto de Renda à importação de softwares; além dos benefícios também provenientes do regime das zonas francas.

Há no Uruguai, também, alguns programas de apoio ao setor de software, dentre os quais, destacam-se: (i) PASS - Programa de Asistencia al Sector Software, que durou de 2002 a 2005, com fundos do FOMIN e BID, com a finalidade de contribuir para o aumento da competitividade das pequenas empresas de software uruguaias, realizando atividades de capacitação e consultoria; (ii) PDT - Programa de Desarrollo Tecnológico, com vistas a mobilizar o potencial de inovação no país e a fortalecer a competitividade produtiva, em especial de pequenas e médias empresas, e melhorar o desenvolvimento científico e tecnológico por meio de incentivos creditícios por um período de cinco anos, advindos em sua maioria do Banco Interamericano de Desenvolvimento (BID); (iii) a Incubadora de Empresas INGENIO, projeto entre o Laboratório Tecnológico do Uruguai e a Universidade ORT, apoiado pelo BID; (iv) PACC - Programa de Apoyo a la Competitividad de Conglomerados, também apoiado pelo BID e que incentiva projetos para fortalecer a competitividade do Conglomerado de Softwares e Serviços de Informática; (v) CES - Centro de Ensayos de Software, subprojeto do projeto "Desenvolvimento tecnológico em setores-chave da economia uruguaia", que conta com financiamento da União Europeia, que tem por objetivo melhorar a qualidade de produtos da indústria uruguaia de software.

Quanto aos êxitos da indústria uruguaia de TICs e de softwares, cumpre destacar a expressividade na exportação de softwares financeiros, a exportação de ferramentas de desenvolvimento de softwares, as alianças estratégicas com multinacionais em mercados verticais, a inserção em cadeias de valor a partir da prestação de serviços e a inovação em modelos de negócios ${ }^{43}$.

Ademais, faz-se necessário salientar a estratégia da exportação de serviços de empresas uruguaias através da instalação de filiais e franquias no exterior, estabelecendo a presença física de companhias uruguaias do

43 GONZÁLEZ, Irene; PITTALUGA, Lucía. El sector de software y servicios informáticos en Uruguay: complementación productiva intra Mercosur en El marco de las estrategias de internacionalización de las empresas uruguayas. Febrero, 2007. Disponível em: <http:// goo.gl/Q2eg6f >. Acesso em: 27 abr. 2015. 
setor em outros países, em plena execução do processo global de transnacionalização das empresas nacionais. Nesse diapasão, uma prática relevante instituída mundialmente para a expansão dos setores de serviços é o denominado outsourcing offshore. Este consiste na transferência de atividades às nações onde estas possam ser efetuadas com custos menores que aqueles dos países de origem, impulsionando as vantagens comparativas da instalação e desenvolvimento dos negócios no exterior $^{44}$.

Não se pode olvidar da importância das zonas francas no Uruguai para o desenvolvimento e comercialização de serviços de TIC e softwares ${ }^{45}$. Atualmente, existem 12 zonas francas no país, das quais 4 (Aguada Park; World Trade Center, Zonamérica e Parque de las Ciencias) se dedicam majoritariamente à comercialização de serviços. ${ }^{46}$ Dentre os benefícios usufruídos pelas empresas que nelas se instalam, pode se destacar: isenção total de impostos (salvo contribuições especiais para a seguridade social); isenção de impostos sobre valor agregado (IVA); possibilidade de comprar insumos e equipamentos novos e usados, sem impostos ou encargos aduaneiros e livre circulação de capitais e livre repatriamento dos lucros. ${ }^{47}$

Demonstradas as iniciativas conferidas ao setor de TIC e softwares no Brasil e Uruguai, o que se preconiza é a necessidade de uma futura simbiose entre os subsetores de ambos os países através de complementação produtiva.

\subsection{Brasil e Uruguai: Complementaridade Produtiva?}

$\mathrm{Na}$ atual dinâmica de fragmentação da cadeia produtiva, a procura por parcerias comerciais se demonstra fundamental para se alcançar preços competitivos no

44 Uruguai tem se tornado um centro de outsourcing, abrangendo companhias que seguem esse modelo, por exemplo, a Tata Consultancy Services, que encontrou no Uruguai um ambiente com boa formação de recursos humanos e possibilidade de um fuso horário oposto ao de sua matriz na Índia, o que beneficia os seus clientes, que podem desfrutar de um serviço 24 horas.

45 As zonas francas no Uruguai são regulamentadas pela Lei ${ }^{\circ}$ 15.921, de 17 de dezembro de 1987.

46 URUGUAY XXI. Zonas Francas no Uruguai. Disponível em: <http://www.uruguayxxi.gub.uy/investimentos/wp-content/ uploads/sites/5/2014/11/Zonas-Francas-no-Uruguai-UruguayXXI.pdf $>$. Acesso em: 5 jun. 2016.

47 AGUADA PARK. Zonas Francas: Beneficios Legales que el Estado Prevee para su Empresa. Disponível em: < http://www.aguadapark. com/zonas-francas-uruguay.html>. Acesso em: 6 jun. 2016. mercado mundial. No âmbito do Mercosul, ainda são tímidas as iniciativas de empreendimentos conjuntos que visam somar esforços na abertura do mercado internacional para as empresas do bloco econômico.

Essa complementação produtiva tanto entre empresas uruguaias de TIC e de softwares e empresas provenientes de outros Estados Partes do Mercosul quanto empresas brasileiras, também prestadoras desse tipo de serviço, ainda é escassa. Um dos principais motivos para isso é a falta de disposição empresarial para cooperação e o fraco incentivo governamental ${ }^{48}$.

Devido à fácil mobilidade e à rapidez com a qual os serviços de TIC e softwares podem ser prestados, entende-se que este poderia ser um setor-chave para a promoção do comércio não só entre Brasil e Uruguai, mas também de todo o Mercosul. O desenvolvimento dessa atividade desempenha um papel fundamental na crescente economia baseada no conhecimento (knowledge-based economy) e nas suas ramificações cada vez mais presentes nas telecomunicações, comércio eletrônico e fluxo de dados.

Ocorre que, com a fragmentação da produção, em que empresas buscam ganhar vantagem competitiva em um ambiente cada vez mais dinâmico e permeado pelas cadeias globais de valor, os investimentos em TIC e softwares se colocam como uma questão estratégica central. Uma cadeia global de valor consiste na ampla gama de atividades que as firmas se engajam para inserir um produto no mercado, desde a concepção até o uso final. Essas atividades englobam o design, produção, marketing, logística e distribuição para dar suporte até o consumidor final. Essas atividades podem ser realizadas pela mesma firma ou divididas entre várias empresas e, como há uma distribuição das atividades em diferentes partes do globo, estas têm se tornado cada vez mais globais. $^{49}$

Logo, os serviços de TIC e softwrares encaixam-se na dinamicidade da cadeia global de valor ao passo que

48 GONZÁLEZ, Irene; PITTALUGA, Lucía. El sector de software y servicios informáticos en Uruguay: complementación productiva intra Mercosur en El marco de las estrategias de internacionalización de las empresas uruguayas. Febrero, 2007. Disponível em: <http:// goo.gl/Q2eg6f >. Acesso em: 27 abr. 2015.

49 ORGANISATION FOR ECONOMIC CO-OPERATION AND DEVELOPMENT. Interconnected economies: Benefiting from global value chains. OECD. 2013. Disponível em:<https://www. oecd.org/sti/ind/interconnected-economies-GVCs-synthesis. pdf>. Acesso em: 06 jun. 2016. p. 8. 
contribui para o fluxo de informações e envolve "todos os aspectos de computadores (hardware e software), sistemas de informação, telecomunicação e automação de escritórios." ${ }^{\circ 0}$ Ao se possibilitar um aumento na velocidade de transmissão e na capacidade de dados, reduz-se os custos e aumenta-se a competitividade. Cada vez mais as empresas se utilizam de tecnologia da informação nas cadeias de suprimento com o intuito de obter vantagem competitiva e automatização dos processos produtivos $^{51}$.

Com base na presente pesquisa, pode se afirmar que tanto o Uruguai quanto o Brasil possuem regimes avançados de incentivo ao desenvolvimento de projetos nessa área. O Brasil já se destaca entre os países mais dinâmicos em economia criativa ${ }^{52}$ e o Uruguai é reconhecido pela alta qualificação da mão de obra de sua população. Essas duas qualidades poderiam ser combinadas de modo a se desenvolver iniciativas de cooperação entre os dois países nesse promissor ramo econômico.

Dentre possíveis empreendimentos conjuntos, aponta-se para a complementariedade dos regimes das Zonas Francas no Uruguai e do Porto Digital de Recife. Ambos os projetos apresentam benefícios para atração e instalação de empresas do setor de TIC e softwares que vão desde isenções tributárias a valores mais convidativos de instalação. Nacionalmente, eles já se destacam como polos de pesquisa e desenvolvimento desse setor. Cumpre agora transformar essa relevância nacional em regional a partir de projetos de cooperação que garantam, por exemplo, a implementação de projetos em conjunto, o livre fluxo de informações, uma infraestrutura robusta de acesso à internet, à banda larga, e a isenção de encargos tributários de serviços comercializados entre essas duas áreas. Essa iniciativa seria pioneira tanto

50 MAÇADA, Antonio Carlos Gastaud; FELDENS, Luis Felipe; SANTOS, André Moraes dos. Impacto da tecnologia da informação na gestão das cadeias de suprimentos: um estudo de casos múltiplos. Gest. Prod., São Carlos, v. 14, n. 1, p. 1-12, jan./abr. 2007. p. 3.

51 MAÇADA, Antonio Carlos Gastaud; FELDENS, Luis Felipe; SANTOS, André Moraes dos. Impacto da tecnologia da informação na gestão das cadeias de suprimentos: um estudo de casos múltiplos. Gest. Prod., São Carlos, v. 14, n. 1, p. 1-12, jan./abr. 2007. p. 3.

52 "Economia criativa é um termo criado para nomear modelos de negócios ou gestão que se originam em atividades, produtos ou serviços desenvolvidos a partir do conhecimento, criatividade ou capital intelectual de indivíduos com vistas a geração de trabalho e renda" SERVIÇO BRASILEIRO DE APOIO ÀS MICRO E PEQUENAS EMPRESAS. O que é economia criativa. Disponível em: $<$ http://www.sebrae.com.br/sites/PortalSebrae/artigos/o-que-eeconomia-criativa,3fbb5edae79e6410VgnVCM2000003c74010aRC RD>. Acesso em: 5 jun. 2016. de forma bilateral quanto regional, visto que, até o momento, não existem iniciativas parecidas na área, apesar de sua grande valorização nos dias atuais.

O setor de TIC e softwares desses dois países devem superar a visão de que, por serem geograficamente localizados na mesma região serão competidores, mas sim unir forças para superarem entraves parecidos. Aproveitando a proliferação da estrutura de outsourcing offshore, seria conveniente para ambos os países acordarem facilidades e preferências para esse tipo de expansão empresarial de empresas provenientes de um território no outro. Assim, aproveita-se a proximidade geográfica e cultural de Brasil e Uruguai para o fomento e aprofundamento dos setores de TIC e softwares, afastando a possibilidade de somente um jogo de soma zero para cada país, mas sim prevalecendo um jogo de soma positivo, característico do processo de integração.

Além disso, essa integração poderia providenciar a inserção de Brasil e Uruguai nas cadeias globais de valor, tornando-se uma iniciativa para tentar desconcentrá-las da região asiática, haja vista que essa localidade ainda é preferida em função de seu maior progresso tecnológico e de seus menores custos de produção e comercialização. Assim, com a concretização dessa iniciativa de integração entre as zonas francas do Uruguai e do Porto Digital do Recife, a América do Sul poderia ser vista como real alternativa para as empresas que se utilizam das cadeias globais de valor em relação a serviços de TIC e software.

\section{Considerações finals}

O setor de serviços vem ganhando cada vez mais importância nas economias tanto do Brasil quanto do Uruguai. Todavia, faz-se necessário que esses países promovam políticas de cooperação efetivas em subsetores relevantes. Essa iniciativa poderia, dentre outros benefícios, fomentar uma cadeia produtiva a ser regionalizada, diminuindo as barreiras como um todo e promovendo maior cooperação entre os Estados, bem como entre seus empresários.

O setor de TIC e de softwares trata-se de exemplo significativo em que essa falta de coordenação entre os dois países se torna visível. Apesar de o Brasil atuar de forma relevante na produção e comercialização dessa esfera de subserviços, inclusive com certos auxílios go- 
vernamentais e o Uruguai ser um grande incentivador desse tipo de subserviços, observa-se que a complementação produtiva entre as empresas de TIC e de softwares desses países, bem como entre eles e as empresas de outros países do Mercosul, ainda é escassa. Ocorre que, por envolver diretamente componentes tecnológicos, e fazerem parte, diretamente, da cadeia de produção, esse setor informatizado pode ser uma chave para a alavancagem dessas duas áreas em ambos os países, se esses conversarem entre si e cooperarem, seja para troca de informações, seja para a complementariedade por meio de ações conjuntas, de modo a avançar a integração também nesse subsetor

Tendo em vista a importância da área de serviços, o presente trabalho propõe, portanto, que Brasil e Uruguai promovam a negociação de novos acordos e políticas de cooperação entre os setores de TIC e softwares dos dois países para que haja troca de tecnologia e fortalecimento da demanda interna desses Estados e uma expansão produtiva entre os dois países em função de sua proximidade geográfica e cultural. Nesse aspecto, aponta-se para a conveniência de se desenvolver uma iniciativa de cooperação entre os regimes de zonas francas do Uruguai e do Porto Digital (Pernambuco) do Brasil. Caberia, assim, instituir um mecanismo legal de modo a propiciar a elaboração conjunta de softwares e prestação de serviços de tecnologia da informação e comunicação.

Por fim, é latente que deve haver maior incentivo por parte dos governos locais para que impulsionem seus setores e empresários a interagirem uns com os outros. Enfatiza-se que o processo de integração econômica deve ser aquele em que todas as partes ganham, não apenas um dos lados.

\section{REFERÊNCIAS BIBLIOGRÁFICAS}

AGUADA PARK. Zonas Francas: Beneficios Legales que el Estado Prevee para su Empresa. Disponível em: <http://www.aguadapark.com/zonas-francas-uruguay. html>. Acesso em: 6 jun. 2016.

ALMEIDA, Paulo Roberto de. Brazilian Trade Policy in Historical Perspective: constant features, erractic behavior. Revista de Direito Internacional, Brasília, v. 10, n. 1, p. 11-23, 2013.
ALVES, Gleisse Ribeiro. O Acordo GATS e sua aplicação aos serviços do comércio eletrônico. Revista de Direito Internacional, Brasília, v. 12, n. 2, p. 321-336, 2014.

ARSLANIAN NETO, Michel. A liberalização do comércio de serviços do Mercosul. Brasília: FUNAG, 2010.

ASSOCIAÇÃO BRASILEIRA DAS EMPRESAS DE TECNOLOGIA DA INFORMAÇÃO E COMUNICAÇÃO. Brasil TI-BPO. Book 2013-2014. Disponível em: <http://goo.gl/ERNUdN>. Acesso em: $20 \mathrm{fev}$. 2015.

ASSOCIAÇÃO BRASILEIRA DAS EMPRESAS DE TECNOLOGIA DA INFORMAÇÃO E COMUNICAÇÃO. 2014/2015: Os condutores do mercado de TIC. Disponível em: <http://goo.gl/ERNUdN>. Acesso em: 23 mar. 2015.

BANCO CENTRAL DO BRASIL. Sistema de Pagamentos em Moeda Local - SML. Disponível em: < http:// www.bcb.gov.br/?SMLINTRO>. Acesso em: 28 jan. 2015.

BRASIL. Ministérios do Desenvolvimento, Indústria e Comércio Exterior. Notas Metodológicas dos dados do SISCOSERV. MDIC. 2016. Disponível em: <http://www.mdic.gov.br//sitio/interna/interna. php?area $=4 \&$ menu $=4998>$. Acesso em: 07 jan. 2016.

BRASIL. Ministérios do Desenvolvimento, Indústria e Comércio Exterior. Negociações Mercosul-União Europeia. MDIC. Disponível em: <http://www.desenvolvimento.gov.br $/$ sitio $/$ interna $/$ interna.php?area $=5 \&$ menu $=26$ 35\&refr=1893 > . Acesso em: 15 mar. 2015.

BRASIL. Ministérios do Desenvolvimento, Indústria e Comércio Exterior. Notas Metodológicas dos dados do SISCOSERV. MDIC. Disponível em: <http:/ /www.mdic.gov. $\mathrm{br} / /$ sitio $/$ interna $/$ interna.php? area $=4 \& \mathrm{menu}=4998>$. Acesso em: 22 jun. 2015.

BRASIL. Ministérios do Desenvolvimento, Indústria e Comércio Exterior. Serviços: Panorama do Comércio Internacional Dados Consolidados de 2012. MDIC. 2013. Disponível em: <http://goo.gl/3QJQdX >. Acesso em: 27 abr. 2015.

BRASIL. Ministérios do Desenvolvimento, Indústria e Comércio Exterior. Serviços: Panorama do Comércio Internacional Dados de 2014. MDIC. 2015. Disponível em: <http://www.mdic.gov.br//arquivos/ dwnl_1431972666.pdf>. Acesso em: 22 jun. 2015. 
BRASIL. Ministérios do Desenvolvimento, Indústria e Comércio Exterior. Serviços: Perfil dos negócios bilaterais 2014. MDIC. 2015b. Disponível em: < http://www. mdic.gov.br//arquivos/dwnl_1432054087.pdf >. Acesso em: 22 jun. 2015.

BRASIL. Ministérios do Desenvolvimento, Indústria e Comércio Exterior. Perfil dos negócios em serviços: Brasil e os países da copa 2014. MDIC. 2014. Disponível em: <http://www.mdic.gov.br/arquivos/ dwnl_1407760950.pdf>. Acesso em: 27 abr. 2015.

CÁMARA URUGUAYA DE TECNOLOGÍAS DE LA INFORMACIÓN. El mercado de software en Uruguay. Oficina Económica Y Comercial De la Embajada De España en Montevideo. Notas Setoriales. Marzo, 2006. Disponível em: <http://www.cuti.org.uy/documentos/software_uruguay.pdf $>$. Acesso em: 23 mar. 2015.

CELLI JÚNIOR, Umberto. Comércio de serviços na OMC: liberalização, condições e desafios. Curitiba: Juruá, 2009.

CELLI JÚNIOR, Umberto. La industria TIC en Uruguay. Ago. 2014. URUGUAY XXI. Disponível em: <http:/ / goo.gl/65a3MW >. Acesso em: 10 fev. 2015.

CELLI JÚNIOR, Umberto. Os acordos de serviços (GATS) e de investimentos (TRIMS) na OMC: espaço para políticas de desenvolvimento. Centro Brasileiro de Relações Internacionais, Ano 2, v. 1, p. 126, 2007.

\section{CONFEDERAÇÃO}

NACIONAL

DAS

INDÚSTRIAS. Serviços e indústria: o elo perdido da competitividade. Brasília: CNI, 2014. Disponível em: <http://goo.gl/RBLyst >. Acesso em: 20 fev. 2015.

FEIJÓ, Camila de Freitas. O Atual Sistema de Solução de Controvérsias do Mercosul: rumo à consolidação de um tribunal regional. Revista de Direito Internacional, Brasília, v. 9, n. 1, p. 69-89, jan. /jun. 2012.

FUNDAÇÃO ALEXANDRE DE GUSMÃO. BrasilUruguai: Os próximos 20 anos. Palácio Itamaraty, Rio de Janeiro, em 22 de julho de 2011. Brasília: FUNAG, 2011. Disponível em: <http://goo.gl/aIaFhh > . Acesso em: 27 abr. 2015.

GARI, Gabriel. The liberalization of Trade in Services in Mercosur. Centre for Commercial Law Studies. Londres: University of London, 2008.

GONZÁLEZ, Irene; PITTALUGA, Lucía. El sector de software y servicios informáticos en Uruguay: complementación productiva intra Mercosur en El marco de las estrategias de internacionalización de las empresas uru- guayas. Febrero, 2007. Disponível em: <http://goo.gl/ Q2eg6f >. Acesso em: 27 abr. 2015.

HORN, H.; MAVROIDIS, P.; SAPIR, A. Beyond the WTO? An anatomy of EU and US preferential trade agreements. Bruegel Blueprint Series, v. 7, 2009.

INSTITUTO DE ESTUDOS PARA O DESENVOLVIMENTO INDUSTRIAL. Clusters on Sistemas Locais de Produção e Inovação: identificação, caracterização e medidas de apoio. São Paulo: IEDI, Maio de 2002. Disponível em: <http://www.iedi.org.br/admin/ pdf/20030516_clusters.pdf>. Acesso em: 6 jun. 2016.

INSTITUTO DE PROMOCÍON DE INVERSIONES Y EXPORTACIONES DE BIENES Y SERVICIOS. Servicios globales de exportación: Oportunidades de inversión en Uruguay. URUGUAY XXI. 2013. Disponível em: <http://www.smartservices.uy/ innovaportal/v/754/7/innova.front/reportes.html>. Acesso em: 19 fev. 2015.

LATRILLE, Pierre; LEE, Juneyoung. Services Rules in Regional Trade Agreements: How diverse and how creative as compared to the GATS multilateral rules. WTO working paper, 2012. Disponível em: < https://goo.gl/ pX8ag7>. Acesso em: 01 maio 2015.

MAÇADA, Antonio Carlos Gastaud; FELDENS, Luis Felipe; SANTOS, André Moraes dos. Impacto da tecnologia da informação na gestão das cadeias de suprimentos: um estudo de casos múltiplos. Gest. Prod., São Carlos, v. 14, n. 1, p. 1-12, jan./abr. 2007.

MARCHETTI, Juan; ROY, Martin. The TISA Initiative: an overview of market access issues. Journal of World Trade, v. 48, n. 4, 2014.

MARCONINI, Mário. OMC, acordos regionais e o comércio de serviços: normativa internacional e interesse brasileiro. São Paulo: Aduaneiras, 2003.

MESQUITA, Paulo Estivallet de. A organização mundial do comércio. Brasília: FUNAG, 2013.

ORGANISATION FOR ECONOMIC CO-OPERATION AND DEVELOPMENT. Interconnected economies: Benefiting from global value chains. OECD. 2013. Disponível em: $<$ https://www.oecd.org/sti/ind/interconnected-economies-GVCs-synthesis.pdf $>$. Acesso em: 06 jun. 2016.

PORTO DIGITAL PARQUE TECNOLÓGICO. Benefícios. Disponível em: <http://www.portodigital.org/ diferenciais/beneficios>. Acesso em: 5 jun. 2016. 
PORTO DIGITAL PARQUE TECNOLÓGICO. O que é o Porto Digital. Disponível em: <http://www.portodigital.org/parque/o-que-e-o-porto-digital>. Acesso em: 5 jun. 2016.

ROY, Martin; MARCHETTI, Juan; LIM, Hoe. Services liberalization in the new generation of preferential trade agreements: how much further than GATS? WTO working-paper. 2006. Disponível em: <https://www.wto.org/ENGLISH/res_e/ reser_e/ersd200607_e.pdf>. Acesso em: 01 maio 2015.

SAYEG, Fernanda Manzano. O tratamento de questões relacionadas a serviços nos acordos regionais de comércio: uma análise dos modelos adotados por Estados Unidos, União Europeia, China e Índia com vistas ao desenvolvimento de um modelo adequado e desejável para o Mercosul. 2014. 310f. Tese (Doutorado em Direito) - Faculdade de Direito da Universidade de São Paulo, São Paulo, 2014.

SERVIÇO BRASILEIRO DE APOIO ÀS MICRO E PEQUENAS EMPRESAS. O que é economia criativa. Disponível em: <http://www.sebrae.com.br/sites/PortalSebrae/ artigos/o-que-e-economia-criativa,3fbb5edae79e6410VgnV CM2000003c74010aRCRD>. Acesso em: 5 jun. 2016.

THORSTENSEN, Vera. OMC Organização mundial do comércio: regras do comércio internacional e a nova rodada de negociações multilaterais. 2. ed. São Paulo: Aduaneiras, 2001.
TRIBUNAL PERMANENTE DE REVISÃO DO MERCOSUL. Tratado de Assunção. TPR. Disponível em: <http://www.tprmercosur.org/pt/docum/Tratado_de_Assuncao_pt.pdf>. Acesso em: 15 mar. 2015.

URUGUAY XXI. Zonas Francas no Uruguai. Disponível em: <http://www.uruguayxxi.gub.uy/investimentos/ wp-content/uploads/sites/5/2014/11/Zonas-Francas-no-Uruguai-Uruguay-XXI.pdf $>$. Acesso em: 5 jun. 2016.

WORLD TRADE ORGANIZATION. 2012 Uruguay Trade Policy Review. WTO. Disponível em: <https:// www.wto.org/english/tratop_e/tpr_e/tp363_e.htm>. Acesso em: 15 fev. 2015.

WORLD TRADE ORGANIZATION. 2013 Brazil Trade Policy Review. WTO. Disponível em: <http://www. wto.org/english/tratop_e/tpr_e/tp383_e.htm>. Acesso em: 15 fev. 2015.

WORLD TRADE ORGANIZATION. 2013 Trade Profile Brazil. WTO. Disponível em: <http:// stat.wto.org/ServiceProfile/WSDBServicePFView. aspx?:Language $=\mathrm{E} \&$ Country $=\mathrm{BR}>$. Acesso em: 13 fev. 2015. 
Para publicar na Revista de Direito Internacional, acesse o endereço eletrônico www.rdi.uniceub.br ou www.brazilianjournal.org.

Observe as normas de publicação, para facilitar e agilizar o trabalho de edição. 